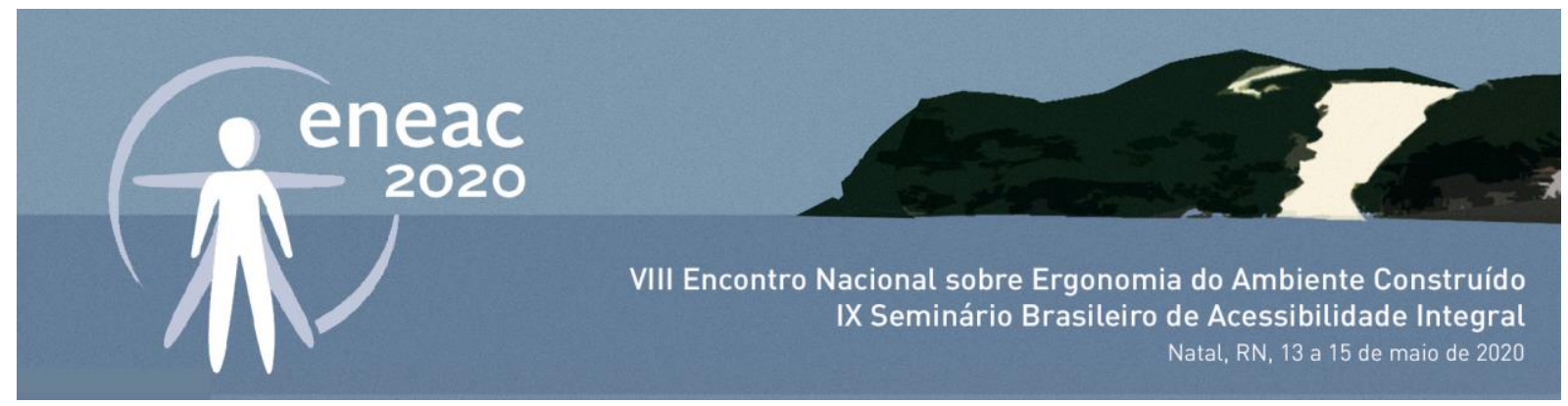

\title{
Fatores da restauração do estresse em recepções hospitalares
}

\author{
Stress restoration factors in hospital receptions
}

\author{
Ana Maria Moreira Maciel \\ Mestre em Gestão Pública, PPGDesign-UFPE, macielana777@gmail.com
}

Vilma Villarouco

Dra. em Engenharia, PPGDesign e PPErgo-UFPE; PPGAU+D-UFC, vvillarouco@gmail.com

\section{RESUMO}

Este trabalho se insere na área de investigação da experiência do estresse em seres humanos, mais especificamente na maneira pela qual ambientes físicos podem contribuir para o enfrentamento do estresse ao exercerem um papel de restauro das capacidades cognitivas e emocionais desgastadas. Descreve a avaliação de cenas de recepções hospitalares, buscando identificar dimensões que derivam dos significados ambientais de segurança e confiança e os atributos físicos que mais influenciam esses julgamentos afetivos. Três cenas de recepções hospitalares, uma julgada como calmante, outra estressante e uma terceira como presumivelmente restauradora foram usadas como elementos de estímulo para coleta de dados através de questionário on-line. Os achados confirmaram que a boa configuração espacial, aliada à visualização de áreas exteriores ajardinadas são elementos claramente promotores das sensações de segurança e confiança. Também se observou que os fluxos e circulações e a disposição do layout são atributos que influenciam nesses julgamentos.

PALAVRAS-CHAVE: Restauração, recepções hospitalares, estresse

\section{ABSTRACT}

This work fits into the area of investigating the experience of stress in human beings, specifically the way in which physical environments can contribute to coping with stress by playing a role in restoring eroded cognitive and emotional capacities. This essay describes the evaluation of hospital reception scenes, seeking to identify dimensions that come from the feelings of security and trust and the physical attributes that most influence these judgments. Three scenes of hospital receptions, one deemed soothing, the other stressful, and the third one presumably restorative were used as stimulus elements for data collection to a questionnaire. The responses were analyzed from graphs and frequency distribuition tables. The results confirmed that spatial configuration, together with the visualization of landscaped outdoor areas, are clearly elements that promote the sensations of security and confidence. It was also observed that flows, circulations, and layout arrangement are attributes that also influence these judgments.

KEYWORDS: Restoration, hospital receptions, stress 


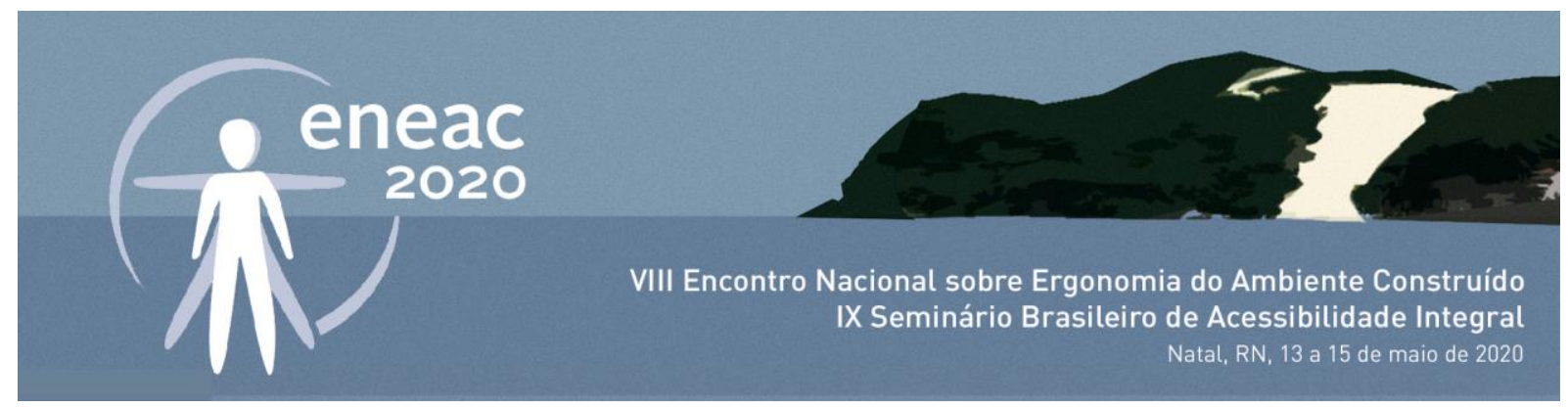

\section{INTRODUÇÃO}

Evidências empíricas demonstram que os edifícios podem influenciar a saúde e o bem-estar humano, e que as escolhas feitas na sua concepção e construção podem tanto beneficiar quanto prejudicar os seres humanos (ULRICH et al., 2008; ANDRADE et al., 2013). O reconhecimento desta influência se reflete na construção ou remodelagem do design e da arquitetura de ambiente hospitalares no sentido de ir ao encontro das necessidades de seus usuários.

Tradicionalmente, o desenho do ambiente físico hospitalar focava apenas no impacto que poderia ser alcançado na eficiência dos cuidados oferecidos, no entanto, nem sempre a funcionalidade dos espaços torna os locais satisfatórios ao aspecto psicológico (ULRICH, 1991).

Para Rodriguez-Marin (1995), quando alguém entra em um hospital, o primeiro impacto é o do ambiente físico, seguido da total falta de intimidade e da transformação da sua vida privada em pública. Segundo esse autor, a hospitalização aparece como um estressor cultural, estressor social, estressor psicológico e físico.

Segundo Ulrich (2008), o estresse pode influenciar os resultados médicos, indicando que, durante a concepção de ambientes de saúde, além de preocupações com o risco de infecções e eficiência funcional, a atenção também deve ser dada às necessidades psicológicas.

Kaplan e Kaplan (1982) destacam que os ambientes hospitalares são estressantes, em parte, por serem, de modo geral, informacionalmente complexos e nada familiares. Para esses autores a longa exposição ao ambiente hospitalar resultaria em cansaço mental e "caos cognitivo".

Importante citar o que colocam Ulrich et al. (1991), quando definem o estresse como uma série de reações psicofisiológicas inter-relacionadas, uma função adaptativa e inata do organismo humano diante de sua relação com um meio estressor. Na tentativa de mitigar ameaças e danos, o indivíduo utiliza recursos pessoais a fim de retornar a uma condição de bem-estar. As reações de estresse uma vez percebida a presença de fatores ameçadores são o estresse psicológico (reações afetivas, cognitivas e comportamentais) e o estresse fisilógico (reações no Sistema Nervoso Central; Sistema Nervoso Autônomo e Sistema Endócrino).

As consequências do estresse para o paciente podem ser evidenciadas tanto no âmbito psicológico (medo, ansiedade, pânico, depressão, etc.), como no âmbito fisiológico (sudorese, tensão muscular, elevação da pressão arterial, entre outras). Essas consequências podem frequentemente refletir no funcionamento imunológico, dificultando o processo de recuperação. Contribuindo nesta construção, cita-se Evans e McCoy (1998) identificaram quatro tipos de situações estressantes: eventos catastróficos, eventos estressantes da vida, complicações cotidianas e ambientes estressantes. Para esses autores, os fatores que causam estresse são de dois tipos: físicos, como iluminação, barulho, poluição e temperatura e psicológicos, que incluem aglomeração e falta de privacidade. Também se pode experimentar o estresse quando o espaço pessoal é invadido, quando há excesso de aborrecimento ou medo.

Em contextos hospitalares, os ambientes de espera representam uma das mais críticas etapas da experiência ambiental, uma vez que essa é marcada por estados emocionais de ansiedade, insegurança, perda de identidade, do reconhecimento social e da autoestima (LEE, 2011). 


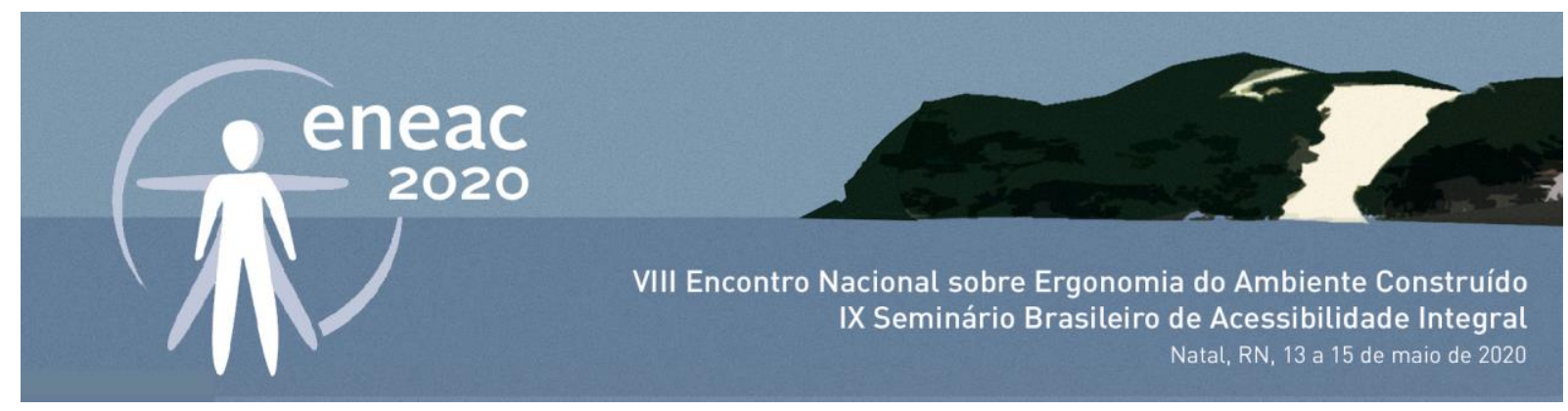

Dessa forma, o conjunto de elementos tangíveis, especificamente o ambiente físico é considerado uma variável importante que influencia a percepção, a atitude e o comportamento dos usuários, podendo levar a comportamentos de aproximação ou rejeição. Para Goldstein (1983, p.289), há uma correlação integral entre comportamento, percepção e forma. Esse autor afirma que "mudando-se a natureza do espaço, é possível modificar simultaneamente os sentimentos das pessoas a respeito do ambiente e o seu comportamento".

A investigação em psicologia ambiental tem demonstrado que o ambiente tem influência nos seus usuários podendo ser potencializador de bem-estar ou de constrangimento. De um modo geral, a investigação mostra que ambientes físicos com certas qualidades permitem o alivio do estresse e representam uma fonte de bem-estar e recuperação daqueles que se encontram nas instituições de saúde, sobretudo os pacientes (ULRICH et al., 2008; ANDRADE et al., 2013).

Destacam-se entre os estudos que buscam otimizar os espaços de atenção à saúde os que tratam da fadiga da atenção e da restauração do estresse. Somam-se a eles os estudos que buscam identificar elementos do ambiente que seriam capazes de diminuir os níveis de estresse presentes na experiência de adoecimento, surgindo correntes de atuação baseadas na "Humanização Hospitalar" e do "Supportive Design".

Dessa forma, a presente pesquisa trata da relação pessoa-ambiente, apoiando-se na Psicologia Ambiental, na Percepção Ambiental e na Ergonomia do Ambiente Construído e se apropriando das técnicas de seleção visual como ferramentas para elucidar os julgamentos perceptuais sobre espaços de recepção hospitalar. A partir do suporte teórico dessas disciplinas, busca-se identificar a relação entre os significados ambientais de segurança e confiança e os atributos físicos presentes em três cenas de recepções hospitalares selecionadas, bem com identificar possíveis correlações entre os atributos físicos e as dimensões da restauração do estresse.

Neste estudo compreende-se a restauração como sendo o processo de recuperação ou renovação dos recursos psicológicos, fisiológicos e sociais dos usuários comprometidos pelas exigências que são colocadas pelos ambientes contemporâneos. Para Ulrich (1991) o ambiente é entendido como restaurador quando há a ausência de demandas estressantes e desperta interesse, prazer ou calma.

\section{REFERENCIAL TEÓRICO}

\subsection{Significados e Atributos Ambientais}

Um dos fatores ligados às reações de estresse em hospitais são os chamados significados ambientais; um aspecto da relação pessoa-ambiente. Significado ambiental pode ser definido como o conjunto de acepções e valores elaborados por alguém acerca do ambiente físico (RAPOPORT, 1990). Para Rapoport (op. cit.), as pessoas observam um contexto físico, identificam e interpretam (social e culturalmente) as informações codificadas na estrutura e essa interpretação pode levar a diferentes modos de ação. As pessoas podem agir de acordo com as mensagens ambientais que elas percebem e, por meio dos seus comportamentos, podem ser fonte de significados para as outras pessoas presentes na cena. É importante notar, no entanto, que Rapoport não define a relação entre ambiente e comportamento como algo determinista.

O Entendimento dos mecanismos de correspondência entre as características fisicas de um lugar e as relações humanas nele manifestadas é de especial importância para quem estuda e planeja os 


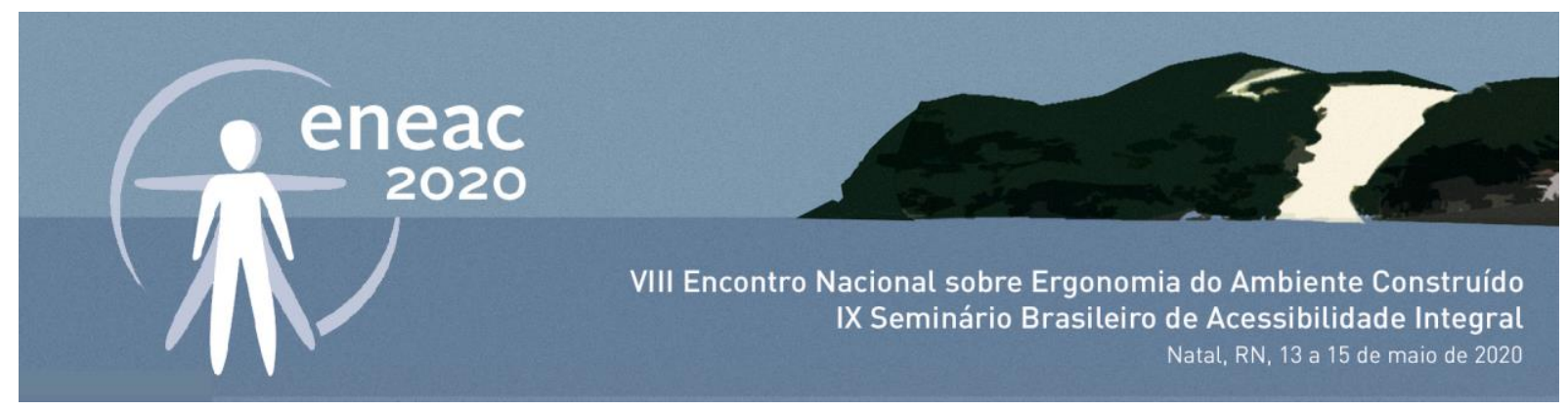

diferentes ambientes, pois possibilita antever e projetar os modos de integração entre as pessoas e seus entornos, facilitando relações desejadas.

A percepção ambiental pode estressar mais ou menos a nossa mente em função do tipo e intensidade dos estímulos visuais. Evans e McCoy (1998) definem "estimulação" como a dimensão que descreve a quantidade de informação imposta ao usuário. Para esses pesquisadores as qualidades ambientais estimulantes podem ser categorizadas levando-se em conta fatores como intensidade, variedade, complexidade, mistério e novidade. Segundo os autores citados, o psicólogo Wohwill identificou em 1974 que os seres humanos funcionam idealmente sob níveis moderados de estimulação. A falta de estimulação leva ao tédio, a estimulação insuficiente pode comprometer a compreensão dos desafios ambientais e a estimulação excessiva pode interferir nos processos cognitivos que requerem atenção, provocando sobrecarga e estresse.

Para Evans e McCoy (1998, p.85), as pessoas precisam do "[...] desafio de pequenas quantidades de variedade no ambiente, complexidade e mistério, para que um nível coerente de solução de problemas possa ocorrer [...]". Para os autores, os extremos e padrões incoerentes de estimulação são, potencialmente, indutores de estresse. Forma, layout, localização e sistemas de circulação incidem diretamente sobre os níveis de estimulação. Elementos como odores desagradáveis, iluminação excessiva, cores fortes, especialmente as saturadas, barulho e complexidade visual exagerada, além de adensamento humano e falta de espaço pessoal podem contribuir para estimulação ou, eventualmente para o estresse (EVANS; MCCOY, 1998).

Para compreender o que pode afetar o comportamento humano em um ambiente construído, é fundamental conhecer os elementos que constituem aquele espaço físico. Cor, luz, som, temperatura, funcionalidade, dimensionamento e mobiliário são alguns dos atributos que podem provocar sensações ao ser humano. Segundo Costi (2002) o paciente é suscetível tanto ao pouco quanto ao excesso de estímulos, pois o cérebro humano necessita de constantes estímulos e variações. "Um ambiente não pode estar sem tensão alguma". No entanto, o que o usuário tem que experimentar deve ser selecionado e limitado, o que significa dizer que as quantidades e os tipos de tensão devem ser previstos.

Em um cenário suficientemente interessante, o indivíduo tende a ser atraído pelo ambiente, reduzindo a pressão psicofisiológica. Assim, é capaz de manifestar respostas positivas, as quais promovem a experiência restauradora (VAN DEN BERG; CUSTERS, 2011). Os espaços devem ser projetados prevendo possibilidade de repouso para quem necessita de paz e tranquilidade, e espaços de estímulo possibilitando uma boa sensação, uma observação estética ou outra emoção qualquer que alivie o sofrimento e a angustia da espera.

Neste texto são associados os significados visuais de segurança e confiança aos atributos fisicos, uma vez que a Teoria Psicoevolucionista, de Roger Ulrich (ULRICH, et al., 1991) - prevê que o processo de restauração seja ativado prontamente a partir da percepção visual de atributos ambientais.

\subsection{Teoria do Design de Suporte e a Restauração em ambientes hospitalares}

Sem sombra de dúvidas o ambiente físico hospitalar pode afetar negativamente pacientes, familiares e profissionais. Para os pacientes e acompanhantes, a hospitalização traz várias situações 


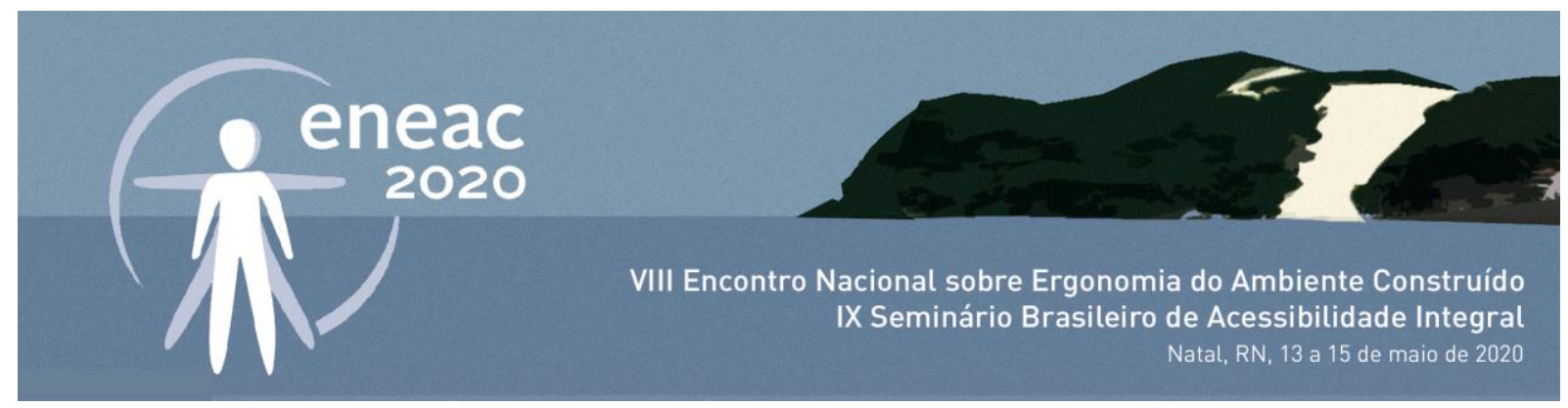

que podem ser estressantes: dificuldade de orientação em um espaço desconhecido; espaços confinados, estranhos e complexos; falta de conforto físico e perda de controle e significado ambiental entre outros.

De acordo com Hartig (2011), as primeiras formulações teóricas e investigações empíricas relacionadas diretamente aos ambientes restauradores datam dos anos 1980, e envolviam discussões acerca de estressores ambientais, aspectos físicos e preferências ambientais. Para o autor citado a restauração pode ser entendida como a recuperação de recursos psicológicos, fisiológicos e sociais comprometidos pelas demandas da vida cotidiana a partir da exposição a ambientes que evocam respostas emocionais positivas, limitando pensamentos negativos que levam ao estresse. Sendo assim, para que um ambiente seja percebido como restaurador, é importante que a pessoa se sinta segura, protegida.

Em relação às teorias que se dedicam a investigar o ambiente restaurador, destacam-se duas vertentes: a Teoria Psicoevolucionista (Psychoevolutionary Theory PET), que visa explicar como determinadas configurações ambientais promovem o restabelecimento dos recursos psicofisiológicos alterados durante uma reação de estresse (ULRICH, et. al., 1991). E a Teoria da Restauração da Atenção (Attention Restoration Theory ART), que explica o processo pelo qual algumas configurações físicas promovem a recuperação da atenção dirigida fadigada durante as mais diversas atividades cotidianas (KAPLAN, 1995).

Roger S. Ulrich propôs em 1983 uma estrutura de redução psicológica do estresse (Psychophysiological Stress Recovery), nela basicamente se enfatiza a percepção visual e estética de certos ambientes e a resposta afetiva a eles associada. De acordo com essa teoria (ULRICH, op. cit.) a restauração dependeria inicialmente das características visuais do meio ambiente, que poderiam evocar rapidamente uma resposta emocional positiva, limitando pensamentos negativos e permitindo que os sistemas psicofisiológicos alterados pelo estresse encontrem um equilíbrio (HARTIG, 2011). O autor propõe que, por uma questão de sobrevivência, o ser humano utiliza estratégias comportamentais que requerem decisões afetivas, como aproximação ou repulsão, além de uma mobilização simultânea de recursos fisiológicos para atender a tais demandas. Esse excesso de tomada de decisões pode causar estresse.

A capacidade restaurativa dos ambientes também atuaria sobre a preferência ambiental, isto é, as pessoas tendem a preferir lugares que permitem a restauração como forma de garantir a satisfação de suas necessidades.

Segundo a abordagem de Ulrich (1991), estar cercado por fatores que estimulem a aproximação e desencorajem certos comportamentos ligados à vigilância é fundamental para o bem-estar e à sobrevivência humana. Os atributos ambientais favoráveis à restauração são traçados por Ulrich como sendo: moderada complexidade; presença de ponto focal; moderada profundidade e limites claros; ordem; superfície pisoteável relativamente uniforme e suave; configuração que favorece a sensação de que os elementos ainda fora do campo visual serão prontamente revelados; ausência de ameaças; presença de água e vegetação (FELLIPE, 2015, p.23).

Fruto dessas reflexões, Ulrich $(1991 ; 2001)$ desenvolveu a Teoria do Design de Suporte onde sugere que o ambiente hospitalar deve proporcionar condições que potencializem a percepção de controle, suporte social e distração positiva e que estas propriedades ambientais são promotoras de bemestar e restauradoras do estresse. 


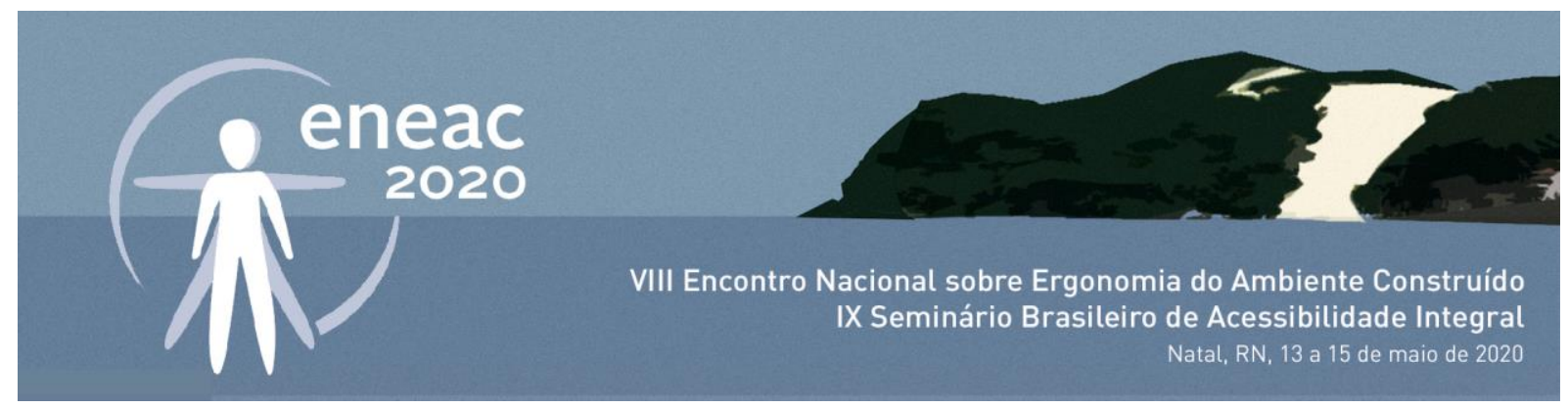

A percepção de controle é um princípio motivacional básico do ser humano, que consiste na crença de que a pessoa tem poder para influenciar não só os seus comportamentos como também para agir sobre o meio circundante e obter os resultados que pretende. Segundo Evans e Cohen (1987), se o indivíduo percebe que tem algum controle sobre um estímulo que lhe provoca estresse, essa percepção poderá minimizar as consequências negativas desse estímulo.

O suporte social caracteriza-se pela crença do indivíduo de possuir um determinado grupo de pessoas nas quais confia e que poderão lhe auxiliar quando de uma situação causadora de estresse. Os ambientes hospitalares são sentidos muitas vezes pelos pacientes como desconhecidos e ameaçadores, pelo que é importante ter acesso ao suporte social promovido por exemplo a partir de espaços de privacidade ou de interação.

A existência de estímulos ambientais positivos (distrações positivas) assume um papel relevante no bem-estar dos indivíduos, em especial nos hospitais (KAPLAN, 1995; ULRICH, 1991). Segundo Kaplan (op. Cit.), o ser humano encontra-se constantemente a realizar um esforço para se manter atento, concentrado e focado relativamente àquilo que tem interesse ou necessita de atenção num determinado momento. A atenção que as diferentes situações do quotidiano exigem, conduz frequentemente à fadiga, aumentando a probabilidade de erros, dificultando a tomada de decisões, assim como o controle das emoções.

A Teoria da Restauração da Atenção, proposta por Rachel e Stephen Kaplan (1989), destaca alguns componentes do espaço como promotores da restauração denominados por Kaplan (1995) como: fascination (fascinação), being away (afastamento); extent (extensão) e compatibility (compatibilidade).

Desta forma, é importante que o indivíduo tenha experiências que captem a atenção involuntária, que possibilitem reflexões e que o transportem psicologicamente, permitindo o afastamento mental de uma determinada situação geradora de estrese a fim de restaurar a sua atenção voluntária (KAPLAN; KAPLAN, 1989). Denominado de afastamento (being away), esse componente diz respeito à capacidade de desligamento que não exige que o espaço seja necessariamente distante. Para Kaplan (1998) os ambientes restauradores podem assumir as mais diversas configurações, embora os que contêm componentes naturais, como a vegetação e água podem contribuir mais facilmente para o processo de redução da fadiga mental.

Fascinação (fascination) é a atenção involuntária, que não exige esforço, permitindo que o sistema da atenção concentrada fadigada descanse (restaure). Em relação às distrações ambientais é importante que o grau de estimulação seja moderado, no sentido em que ambientes com elevada estimulação (luminosidade intensa, cores fortes ou ruidosos) podem se tornar demasiado agitados e estressantes para o indivíduo. Por sua vez, ambientes com baixa estimulação (ausencia de componentes que promovem distração) poderão levar as pessoas a concentrarem-se mais nos seus problemas, o que consequentemente poderá aumentar os níveis de estresse.

Extensão (extent) trata-se da imersão em um ambiente físico coerente, planejado, que possibilita a sua exploração e interpretação. O ambiente deve promover conectividade, ser harmonioso o suficiente para engajar a mente. (GRESSLER; GUNTHER, 2013; KAPLAN, 1995).

Compatibilidade (compatibility) é a conjugação entre as aspirações ou inclinações dos usuários, e o propósito fornecido pelo ambiente para a realização das atividades naquele local (GRESSLER; GÜNTHER, 2013; KAPLAN, 1995). 


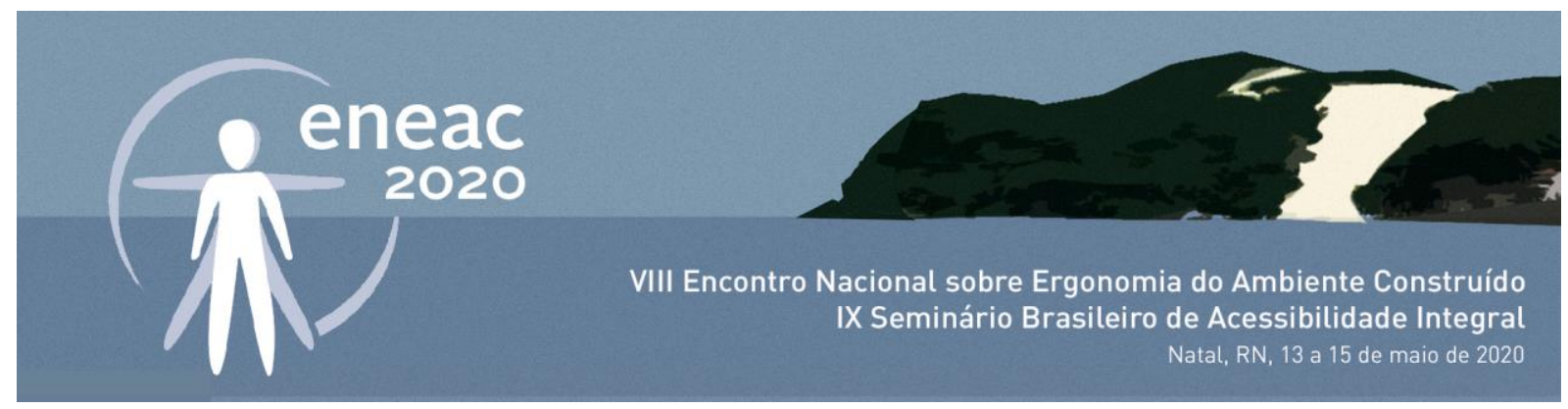

Analisando a produção científica sobre o tema da restauração do estresse em ambientes hospitalares foi possível perceber que uma quantidade expressiva de estudos se dedica ao exame dos ambientes naturais, deixando em segundo plano os ambientes construídos, ou atêm-se ao exame da dicotomia ambiente natural versus ambiente construído, sem identificar o papel de elementos específicos desses ambientes no processo restaurador (VELARDE; FRY; TVEIT, 2007).

Por essa razão, este trabalho teve como foco o ambiente construído. Nesta pesquisa, buscou-se investigar os atributos ambientais proeminentes na percepção ambiental de recepções hospitalares que evocariam respostas emocionais positivas e que promoveriam a restauração do estresse.

\section{METODOS E PROCEDIMENTOS DE PESQUISA}

A pesquisa aqui apresentada é do tipo descritivo-exploratória e busca compreender melhor o processo de restauração do estresse e a correlação com os atributos físicos do ambiente de recepção hospitalar. Do tema proposto foi inicialmente realizada uma revisão bibliográfica e para a coleta de dados foi utilizado o Sistema de Classificações Múltiplas. Costa Filho (2014) destaca que se trata de uma técnica que fornece procedimentos sensíveis para diagnosticar as impressões sobre a experiência no lugar, além de ter como vantagens não depender de declarações verbais e permitir o uso de materiais visuais.

Buscou-se na pesquisa: (i) identificar as cenas associadas às percepções de segurança e confiança; (ii) coligar os atributos físicos que mais influenciam os julgamentos de segurança e confiança e; (iii) identificar os atributos físicos associados às dimensões da restauração (fascinação, afastamento, coerência e compatibilidade).

A Figura 1, cena 1 foi selecionada por ter sido julgada em pesquisa anterior (MACIEL; COSTA FILHO; VILLAROUCO, 2018) como tendo qualidade calmante, possivelmente por apresentar-se moderadamente complexa e com coerência alta. $O$ fato de ser um ambiente moderadamente complexo, conforme aqui referenciado, considera o nível de estímulo para o tipo de função desse tipo de ambiente o que presumivelmente eleva a calma. Os postulados teóricos apontam que a qualidade calmante é aumentada através da complexidade média, uma vez que a complexidade mínima é postulada como monótona e entediante, enquanto a alta é caótica e estressante.

Já a Figura 2, cena de recepção com coerência baixa (contraste alto) e complexidade baixa de seus atributos ambientais, foi percebida na pesquisa anteriormente citada (MACIEL; COSTA FILHO; VILLAROUCO, 2018) como aquela que menos elevava a qualidade calmante percebida.

A Figura 3 foi selecionada por permitir ampla visualização do exterior e, portanto, suscitar fascinação e distração positiva, além de ser dotada de coerência e compatibilidade para o desenvolvimento das funções previstas em uma espera em ambiente hospitalar. 


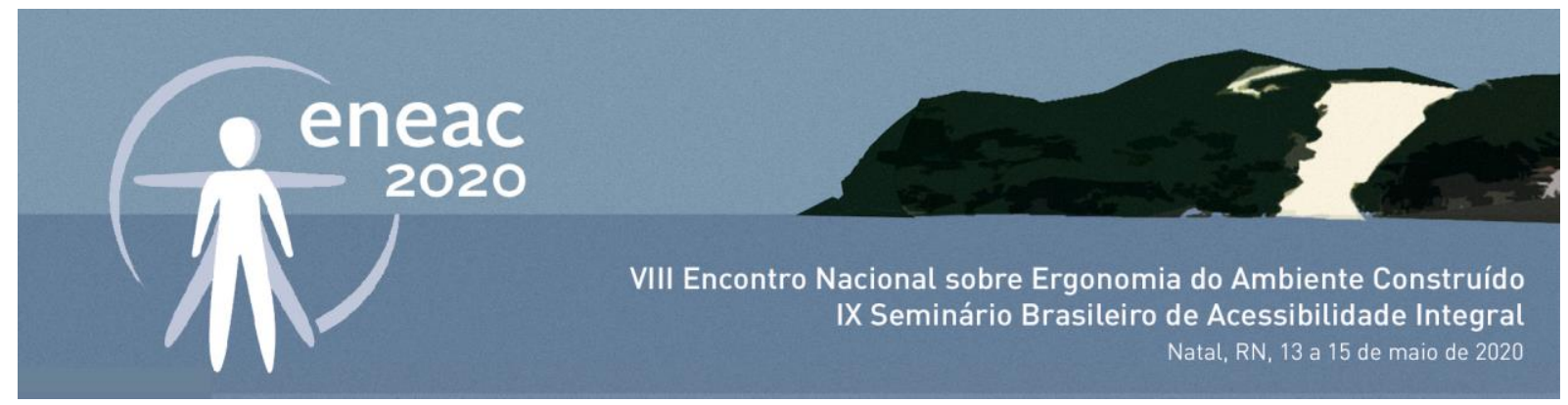

Figura 1: Ambiente de recepção hospitalar calmante - Cena 1

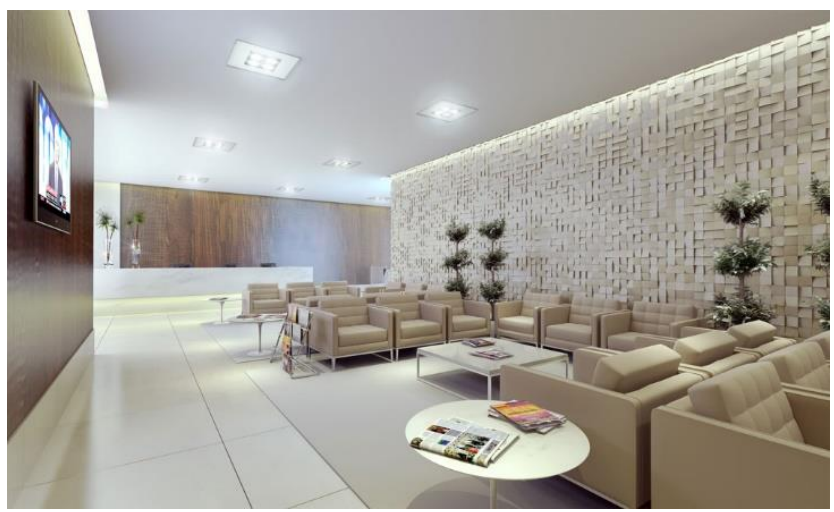

Fonte: Google imagens, 2018

Figura 2: Ambiente de recepção hospitalar estressante - Cena 2

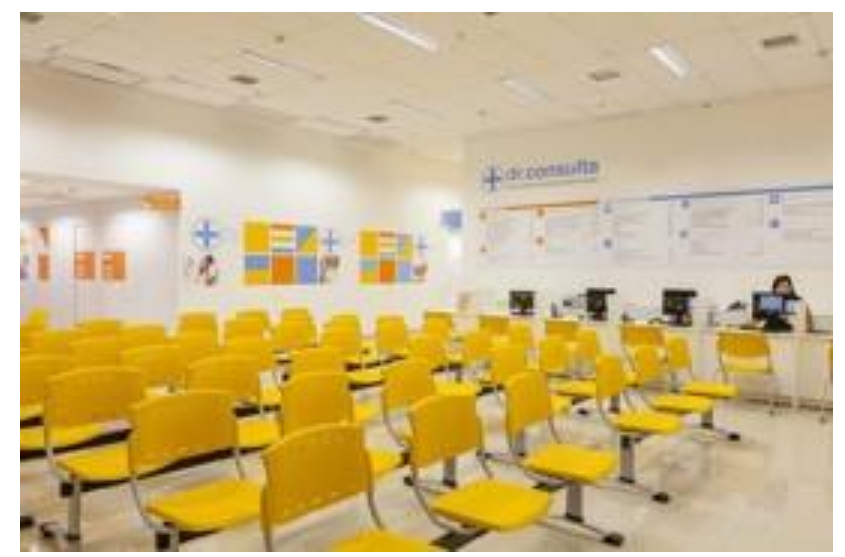

Fonte: Google imagens, 2018

Figura 3: Ambiente de recepção hospitalar restaurador - Cena 3

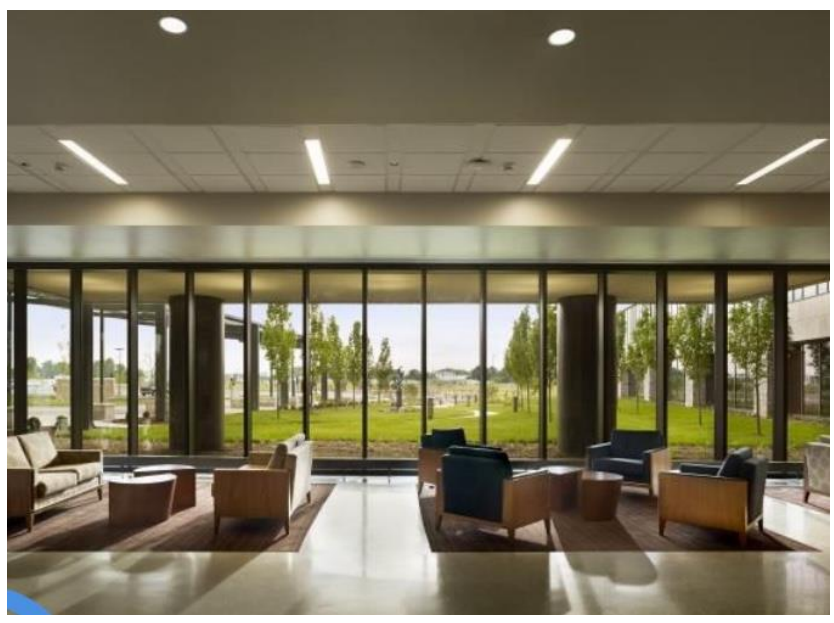

Fonte: Google imagens, 2018 


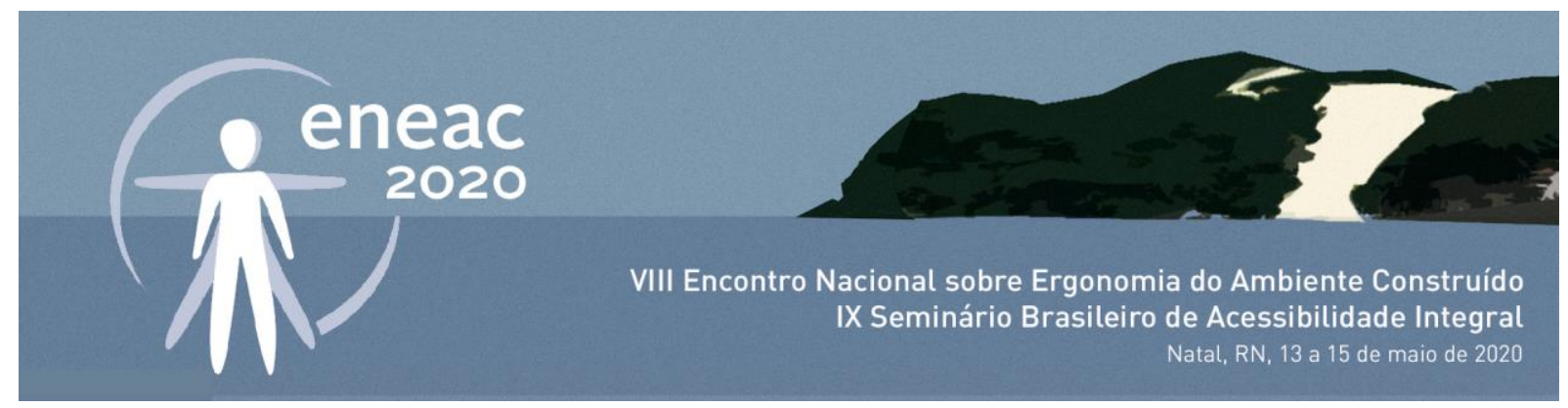

Com relação aos procedimentos de pesquisa, inicialmente foi informado aos respondentes que: (i) o estudo focava na avaliação visual de ambientes de recepção hospitalar; (ii) não havia resposta certa ou errada; (iii) garantia-se o anonimato; (iv) os dados coletados seriam apenas divulgados em comunicações científicas. Em seguida, o participante após se identificar por sexo, idade e nível de escolaridade, era solicitado a classificar as cenas em função da percepção de segurança (segura, relativamente segura e insegura) e confiança (mais confiança, menos confiança, nenhuma confiança).

Depois os participantes eram convocados a indicar quais atributos físicos do ambiente de recepção em sua opinião as tornava mais seguras e confiáveis. Foram investigadas as associações entre os significados ambientais de segurança e confiança com os seguintes atributos ambientais:

Configuração ambiental; Fluxos e circulações; Integração interior/exterior; Leiaute; lluminação; Materiais; Cores; Comunicação Visual; Mobiliário.

Em seguida o mesmo participante era novamente solicitado a identificar os atributos ambientais que mais Ihe chamavam atenção (fascinação); os que lhe permitiriam maior distração; os que se apresentavam visualmente caóticos, confusos ou cansativos e; por fim os julgados inapropriados.

Ao final do período estipulado para coleta de dados, contou-se com a participação de 124 sujeitos, sendo 41 especialistas $(33,1 \%)$ arquitetos ou designers e os demais $83(66,9 \%)$ não especialistas. Como estímulo visual foram selecionadas três cenas de recepções hospitalares com características ambientais diferentes, uma potencialmente calmante, outra estressante e a terceira presumivelmente restauradora. $\mathrm{O}$ tratamento dos dados iniciou-se com a tabulação e posterior análise de gráficos e tabelas de distribuição das frequências das respostas (MARCONI; LAKATOS, 2003).

\section{EVIDÊNCIAS EMPÍRICAS}

Conforme a Tabela 1, à percepção de segurança a Cena 1 recebeu 80 votos $(64,51 \%)$, a Cena 2 recebeu 9 votos $(7,26 \%)$ e a Cena 3 recebeu 64 votos (51,61\%). No quesito confiança a Cena 1 recebeu 73 votos $(58,87 \%)$, a Cena 2 recebeu 12 votos $(9,68 \%)$ e a Cena 3,78 votos $(62,9 \%)$ como pode ser observado na Tabela 2. Acredita-se que as cenas 1 (Fig. 1) e 3 (Fig. 3) foram consideradas as mais seguras e confiáveis presumivelmente por apresentarem características de contraste baixo e complexidade média, ao facilitar a compreensão, favorecer a coerência ao reduzir a incerteza e aumentar o tom hedônico. A Cena 2 (Fig. 2) em função da baixa coerência (contraste alto) e complexidade baixa foi percebida pelos participantes da pesquisa como aquela que menos promovia sensações de segurança e confiança, pois foi considerada aflitiva segundo os respondentes.

Tabela 1: Resultados da percepção de segurança

\begin{tabular}{c|c|c|c|c|c|c} 
Julgamentos & Cena 1 & \% & Cena 2 & \% & Cena 3 & \% \\
\hline Segura & 80 & 64,51 & 9 & 7,26 & 64 & 51,61 \\
\hline Relativamente Segura & 39 & 31,45 & 51 & 41,13 & 44 & 35,48 \\
\hline Insegura & 5 & 4,03 & 64 & 51,61 & 16 & 19,9 \\
\hline \multicolumn{5}{r}{ Fonte: autores, 2019. }
\end{tabular}




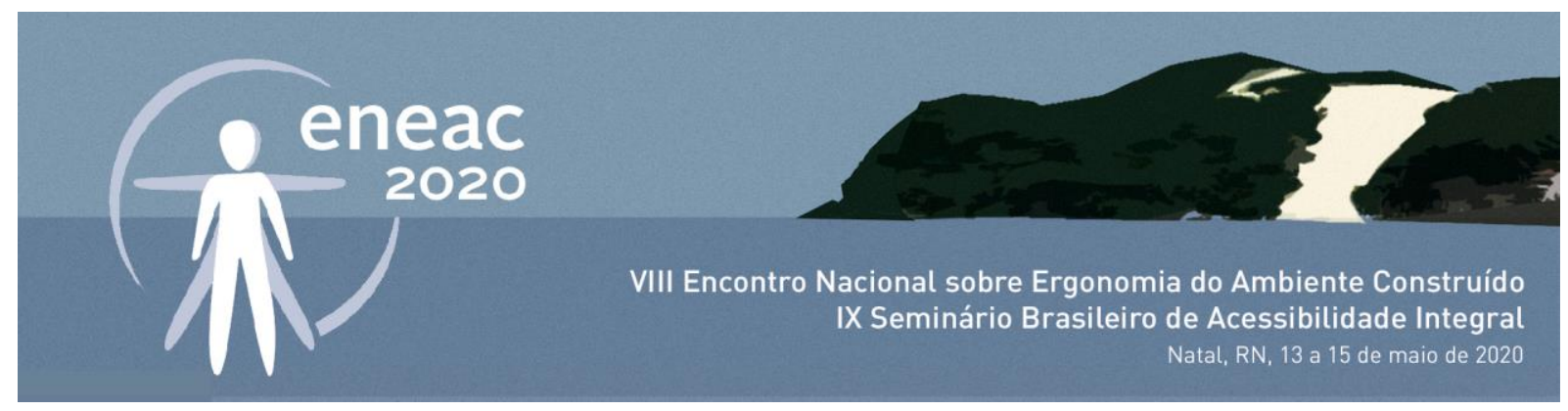

Tabela 2: Resultados da percepção de confiança

\begin{tabular}{c|c|c|c|c|c|c} 
Julgamentos & Cena 1 & \% & Cena 2 & \% & Cena 3 & \% \\
\hline Mais confiança & 73 & 58,87 & 12 & 9,68 & 78 & 62,9 \\
\hline Menos confiança & 40 & 32,26 & 51 & 41,13 & 36 & 29,03 \\
\hline Nenhuma Confiança & 11 & 8,87 & 61 & 49,19 & 10 & 8,06 \\
\hline Total & \multicolumn{7}{c|}{ Fonte: autores, 2019. }
\end{tabular}

Ao analisar as respostas dos entrevistados no que concerne aos atributos físicos associados à sensação de segurança destacam-se a configuração do ambiente $(67,7 \%)$, os fluxos/circulações $(50,0 \%)$ e a integração interior/exterior $(41,1)$ como podemos observar na Tabela 3.

Tabela 3: Resultados da correlação entre atributos físicos e sensação de segurança

\begin{tabular}{c|c|c} 
Atributos Físicos & Menções & $\%$ \\
\hline $\begin{array}{c}\text { Configuração do } \\
\text { Ambiente }\end{array}$ & 84 & 67,7 \\
\hline Fluxos/circulação & 62 & 50,0 \\
\hline $\begin{array}{c}\text { Integração } \\
\text { interior/exterior }\end{array}$ & 51 & 41,1 \\
\hline $\begin{array}{c}\text { Disposição do } \\
\text { Mobiliário/leiaute }\end{array}$ & 46 & 37,1 \\
\hline Iluminação & 48 & 38,7 \\
\hline Materiais & 36 & 29,0 \\
\hline Cores & 30 & 24,2 \\
\hline Comunicação visual & 19 & 15,3 \\
\hline Mobiliário & 34 & 27,4 \\
\hline \multicolumn{2}{c}{ Fonte: autores, 2019.} \\
\end{tabular}

Em relação à sensação de confiança se destacaram na pesquisa, os atributos configuração do ambiente, com 85 menções (68,5\%), disposição do mobiliário com 49 menções (39,5\%) e iluminação com 49 menções $(37,9)$ (Tabela 4).

Tabela 4: Resultados da correlação entre atributos físicos e sensação de confiança

\begin{tabular}{c|c|c} 
Atributos Físicos & Menções & \% \\
\hline $\begin{array}{c}\text { Configuração do } \\
\text { Ambiente }\end{array}$ & 85 & 68,5 \\
\hline Fluxos/circulação & 41 & 33,1 \\
\hline $\begin{array}{c}\text { Integração } \\
\text { interior/exterior }\end{array}$ & 43 & 34,7 \\
\hline $\begin{array}{c}\text { Disposição do } \\
\text { Mobiliário/leiaute }\end{array}$ & 49 & 39,5 \\
\hline Iluminação & 47 & 37,9 \\
\hline Materiais & 39 & 31,5 \\
\hline Cores & 30 & 24,2 \\
\hline Comunicação visual & 21 & 16,9 \\
\hline Mobiliário & 40 & 32,3 \\
\hline \multicolumn{2}{c}{ Fonte: autores, 2019. }
\end{tabular}




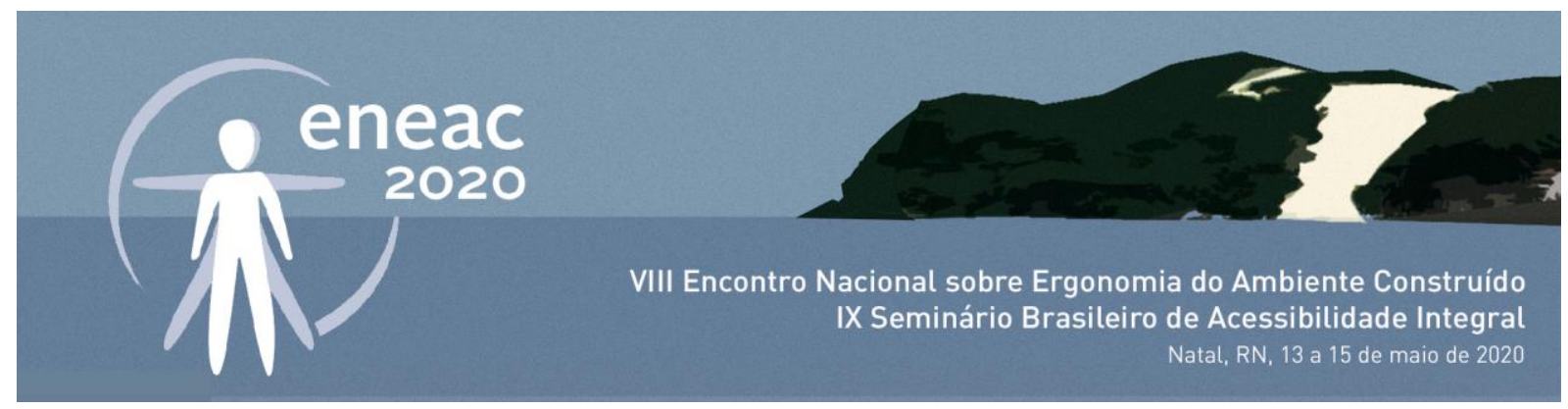

Os resultados encontrados na pesquisa nos permitem concluir a importância da configuração do ambiente para a construção do significado de segurança e confiança, uma vez que, como apontam os pressupostos teóricos apontados por Ulrich (op. Cit.), para ambientes restauradores os atributos fisicos são: moderada complexidade; presença de ponto focal; moderada profundidade e limites claros; ordem; superfície pisoteável relativamente uniforme e suave; configuração que favorecem a sensação de que os elementos ainda fora do campo visual serão prontamente revelados; ausência de ameaças; presença de água e vegetação. A maior parte das características apontadas nos estudos de Ulrich (1991) podem ser observadas na Cena 3.

No que diz respeito às dimensões da restauração, a avaliação de atributos fisicos que permitem a distração das preocupações cotidianas se destacaram a integração exterior/interior com 88 menções $(71,0 \%)$, as distrações positivas com 75 menções $(60,5 \%)$ e a presença de cores com 38 menções $(30,6 \%)$ (Tabela 5).

Tabela 5: Resultados da correlação entre atributos físicos e o componente afastamento (Being away)

\begin{tabular}{|c|c|c|}
\hline Atributos Físicos & Menções & $\%$ \\
\hline $\begin{array}{c}\text { Configuração do } \\
\text { Ambiente }\end{array}$ & 32 & 25,8 \\
\hline Fluxos/circulação & 11 & 8,9 \\
\hline $\begin{array}{c}\text { Integração } \\
\text { interior/exterior }\end{array}$ & 88 & 71,0 \\
\hline Distrações positivas & 75 & 60,5 \\
\hline $\begin{array}{c}\text { Disposição do } \\
\text { Mobiliário/leiaute }\end{array}$ & 30 & 24,2 \\
\hline Iluminação & 33 & 26,6 \\
\hline Materiais & 33 & 26,6 \\
\hline Cores & 38 & 30,6 \\
\hline Comunicação visual & 30 & 24,2 \\
\hline Mobiliário & 33 & 19,4 \\
\hline Nenhum & 5 & 4,0 \\
\hline
\end{tabular}

Portanto, os resultados encontrados na presente pesquisa só vêm a reafirmar achados empíricos anteriores que apontam que ambientes que permitem aquietar a mente, eliminar o excesso de informações e refletir, para só depois tomar decisões são naturalmente ambientes restauradores. É sabido que a possibilidade de visualizar areas externas, em especial as ajardinadas promovem a interrupção de pensamentos negativos, além disso a possibilidade de acesso ao ambiente exterior e a jardins contribui para a percepção de livre movimentação e são importantes para a promoção do controle pessoal e suporte social.

Embora o número expressivo de 50 respondentes $(40,3 \%)$ não tenha identificado nas três cenas analisadas nenhum elemento percebido como inapropriado, os elementos que foram mais destacados para essa categoria de análise foi o mobiliário com 33 votos (26,6\%), a disposição do mobiliário com 24 votos $(19,4 \%)$ e as cores com 21 votos (16,9\%) (Tabela 6). Esses dados corroboram o apontado por Vasconcelos (2004), pois proporcionar mobiliário confortável e arranjos flexíveis para 


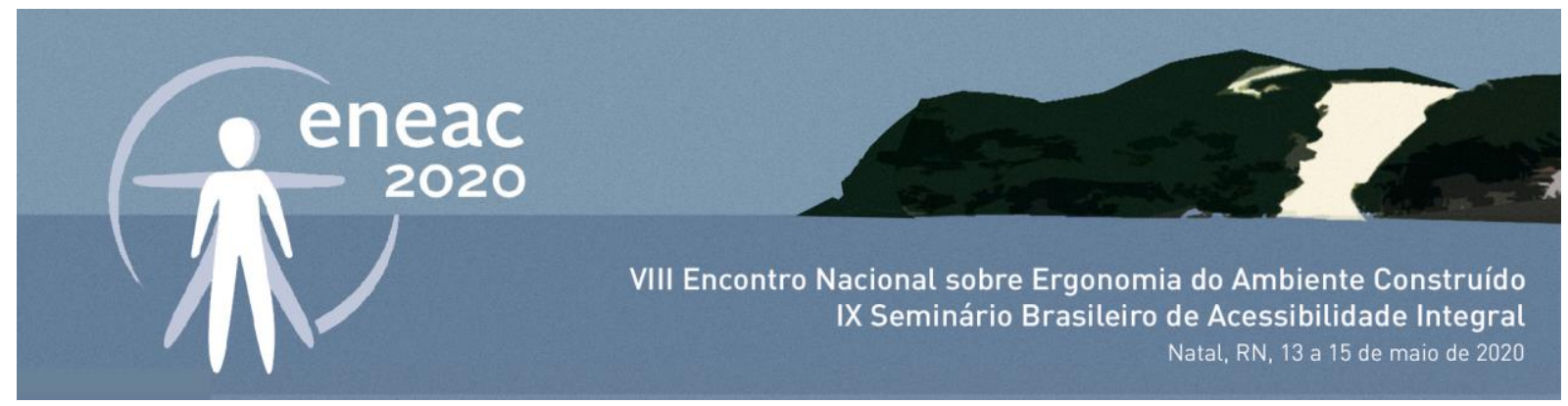

as salas de espera estimula a interação social. Também segundo a citada autora é indicado que se evite cadeiras lado a lado ou encostadas às paredes pois elas reduzem a privacidade.

Tabela 6: Resultados da correlação entre atributos físicos e o componente inapropriados para o uso

\begin{tabular}{c|c|c} 
Atributos Físicos & Menções & $\%$ \\
\hline $\begin{array}{c}\text { Configuração do } \\
\text { Ambiente }\end{array}$ & 11 & 8,9 \\
\hline Fluxos/circulação & 16 & 12,9 \\
\hline $\begin{array}{c}\text { Integração } \\
\text { interior/exterior }\end{array}$ & 4 & 3,2 \\
\hline $\begin{array}{c}\text { Disposição do } \\
\text { Mobiliário/leiaute }\end{array}$ & 24 & 19,4 \\
\hline Iluminação & 8 & 6,5 \\
\hline Materiais & 14 & 11,3 \\
\hline Cores & 21 & 16,9 \\
\hline Comunicação visual & 12 & 9,7 \\
\hline Mobiliário & 33 & 26,6 \\
\hline Nenhum & 50 & 40,3 \\
\hline \multicolumn{2}{c|}{ Fonte: autores, 2019. }
\end{tabular}

Os usuários devem ser capazes de perceber o ambiente como um todo harmonioso e coerente. As proporções entre formas e volumes devem ser agradáveis e permitirem a atuação nesse espaço com autonomia.

Como elementos promotores da atenção soft, fascinação, foram identificados a integração interior/exterior (64,5\%), a configuração do ambiente $(40,3 \%)$ e a iluminação $(38,7 \%)$ (Tabela 7$)$.

Tabela 7: Resultados da correlação entre atributos físicos e o componente inapropriados para o uso

\begin{tabular}{c|c|c} 
Atributos Físicos & Menções & $\%$ \\
\hline $\begin{array}{c}\text { Configuração do } \\
\text { Ambiente }\end{array}$ & 50 & 40,3 \\
\hline Fluxos/circulação & 22 & 17,7 \\
\hline $\begin{array}{c}\text { Integração } \\
\text { interior/exterior }\end{array}$ & 80 & 64,5 \\
\hline $\begin{array}{c}\text { Disposição do } \\
\text { Mobiliário/leiaute }\end{array}$ & 34 & 27,4 \\
\hline Iluminação & 48 & 38,7 \\
\hline Materiais & 48 & 38,7 \\
\hline Cores & 41 & 33,1 \\
\hline Comunicação visual & 27 & 21,8 \\
\hline Mobiliário & 38 & 30,6 \\
\hline Nenhum & 2 & 1,6 \\
\hline \multicolumn{2}{c}{ Fonte: autores, 2019. }
\end{tabular}

A eficácia da simples contemplação da natureza para a restauração mental é largamente documentada nas pesquisas de ambientes hospitalares. A visualização da natureza elicia afetos e significados positivos, constitui-se numa importante distração positiva, atrai o interesse do observador e distrai de preocupações, pensamentos estressantes e mal-estar físico (ULRICH, 1991). 


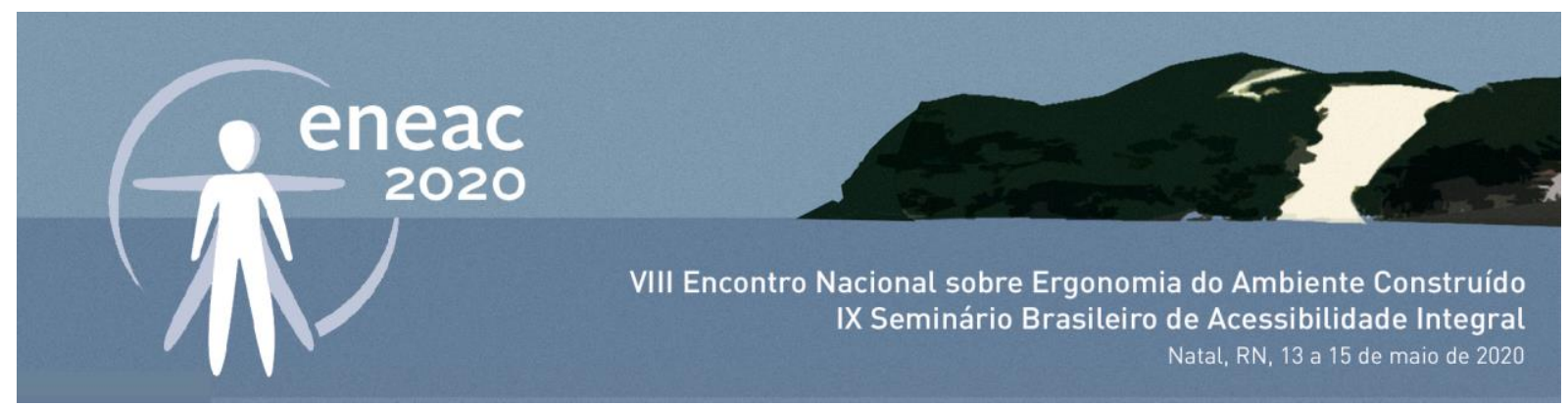

Como atributos físicos das cenas de recepções hospitalares identificados como caóticos, confusos ou visualmente cansativos se destacaram as cores $(38,7 \%)$, a disposição do mobiliário $(38,7 \%)$ e o próprio mobiliário $(34,7 \%)$, conforme apresentado na Tabela 8.

Tabela 8: Resultados da correlação entre atributos físicos e o componente inapropriados para o uso

\begin{tabular}{|c|c|c|}
\hline Atributos Físicos & Menções & $\%$ \\
\hline $\begin{array}{l}\text { Configuração do } \\
\text { Ambiente }\end{array}$ & 20 & 16,1 \\
\hline Fluxos/circulação & 20 & 16,1 \\
\hline $\begin{array}{c}\text { Integração } \\
\text { interior/exterior }\end{array}$ & 7 & 5,6 \\
\hline $\begin{array}{c}\text { Disposição do } \\
\text { Mobiliário/leiaute }\end{array}$ & 48 & 38,7 \\
\hline Iluminação & 13 & 10,5 \\
\hline Materiais & 14 & 11,3 \\
\hline Cores & 48 & 38,7 \\
\hline Comunicação visual & 25 & 20,2 \\
\hline Mobiliário & 43 & 34,7 \\
\hline Nenhum & 20 & 16,1 \\
\hline
\end{tabular}

O layout do ambiente é um fator importante a ser considerado em pesquisa sobre ambientes de recepção hospitalar (LEE, 2011). Esse autor destaca que a disposição dos assentos e os esquemas de cores usadas nessa parte do hospital podem criar espaços sossegados ou estressantes. Tantos pacientes quanto acompanhantes tendem a preferir um ambiente mais relaxante para as áreas de espera. Um elemento importante a ser considerado é a promoção da privacidade e o respeito ao espaço pessoal, qualidades que podem ser conseguidas a partir da disposição do leiaute do mobiliário.

Dessa forma, constatou-se na presente pesquisa que para que as recepções hospitalares contribuam para a restauração do estresse o ambiente construído deve permitir acesso visual às áreas externas, deve promover acessibilidade plena, deve dispor de mobiliário ergonômico, leiaute funcional, iluminação eficiente e estudo cromático que permita a correta utilização das cores.

\section{CONCLUSÃO}

Acreditamos que através da Psicologia Ambiental é possível desconstruir a visão coletiva a respeito dos hospitais como ambientes que comportam apenas sofrimento e dor e contribuir para o resgate da humanização da arquitetura hospitalar.

Na presente pesquisa, ao analisar a qualidade restauradora em cenas de ambientes de recepção hospitalar, apurou-se que a percepção de segurança e confiança são altamente sensíveis aos atributos configuração do ambiente, disposição do mobiliário e integração interior/exterior, confirmando os pressupostos teóricos.

Quanto aos aspectos físicos que interferem na segurança transmitida pelo ambiente, observou-se que as recepções hospitalares que promovem mais segurança são as que a configuração do 


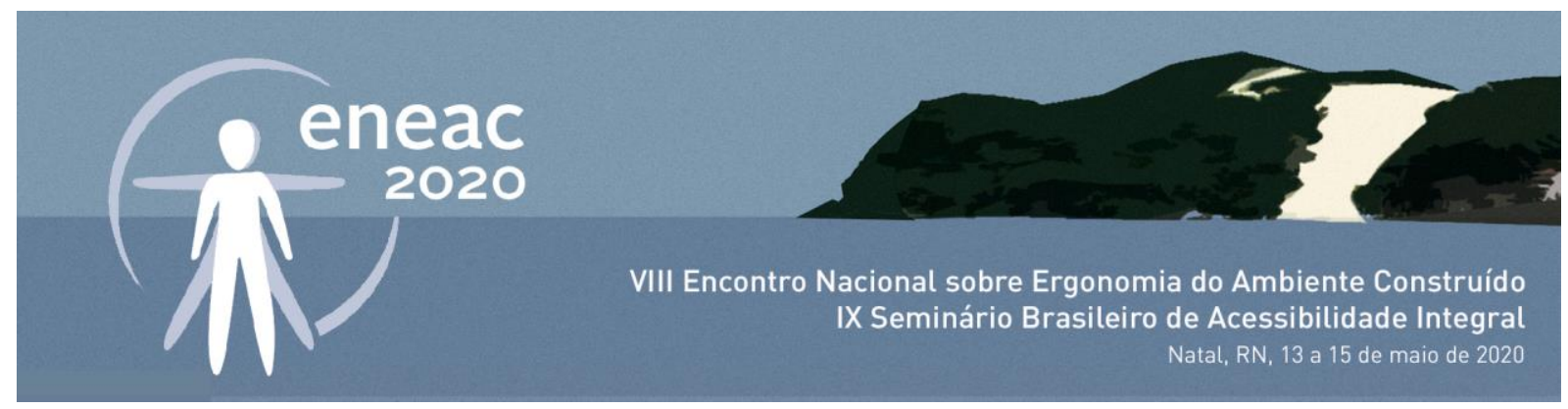

ambiente foi percebida como mais organizada, totalizando $67,7 \%$ das avaliações. 0 fluxo e circulação foram citados por $50 \%$ das pessoas entrevistadas e a integração do interior/exterior totalizou $41,1 \%$ das 124 respostas obtidas.

Para a promoção dos componentes restauradores do espaço, fascinação e afastamento, o atributo integração interior/exterior foi o mais saliente. Com relação ao comprometimento da coerência e compatibilidade do espaço, foram apontados como atributos destacados as cores e a disposição do mobiliário.

Dessa forma é possível acreditar que ao implementar ambientes construídos que integrem o ambiente interior ao exterior; que dispõem de mobiliário confortável e sistemas de ventilação e iluminação otimizados; que atentem para o correto uso das cores em paredes e mobiliários, consegue-se promover significados ambientais positivos, diminuindo o estresse e restaurando os recursos psicológicos desgastados.

Vale a pena destacar que os resultados observados nesta pesquisa não devem ser tomados de maneira simplista uma vez que se trata de uma compreensão para o tipo de elemento de estímulo apresentado aos participantes como suporte para as avaliações, e depende dos grupos investigados, do local e das imagens selecionadas.

\section{REFERÊNCIAS}

ANDRADE, C., LIMA, L., PEREIRA, C., FORNARA, F. AND BONAIUTO, M. Inpatients and Outpatients satisfaction: The mediating role of perceived quality or physical and social environment. Health \& Place, 21, 122-132, 2013.

COSTA FILHO, Lourival L. O enfoque da Teoria das Facetas na avaliação de lugares. In: MONTALVÃO, C.; VILLAROUCO, V. (Orgs.). Um novo olhar para o projeto, 2: a ergonomia no ambiente construído. Recife: Ed. UFPE, P.11-26, 2014.

COSTI, Marilice. A influência da luz e da cor em salas de espera e corredores hospitalares. Porto Alegre: Edipucrs, 2002.

EVANS, G. W., \& MCCOY, S. Environmental stress. In D. Stokols \& I. Altman (Eds.), Handbook of environmental psychology (Vol. 1, pp. 571-610). New York, NY: Wiley, 1998.

FELLIPE, M. L. Ambiente Fisico e Linguaggio ambiental nel processo di rigenerazione affetiva dallo stress in camera di degenza pediátrica (Doutorado em Arquitetura). Universitá degli Atudi di Ferrara, Itália, 2015. Recuperado de http://eprints.unife.it/994/.

GRESSLER, S. C., \& GÜNTHER, I. A. Ambientes restauradores: Definição, histórico, abordagens e pesquisas. Estudos de Psicologia, 18(3), 487-495, 2003.

HARTIG, T. Issues in restorative environments research: Matters of measurement. Psicología ambiental, 41-66, 2011.

KAPLAN S., The restorative benefits of nature: toward an integrative framework, in: "Journal of Environmental Psychology", v. 15, n. 3, 1995 (pp. 169-182).

KAPLAN, R., \& KAPLAN, S. The experience of nature: A psychological perspective. CUP Archive.1989.

LEE, S. Evaluating serviceability of healthcare servicescapes: service design perspective. International Journal of Design, 5 , 61-71, 2011. Retirado de http://www.ijdesign.org/index.php/IJDesign/article/view/919/347.

KOTAKA, F. \& FAVERO, M. Avaliação da organização espacial para a circulação de pessoas em um hospital geral. In: Encontro Nacional de Tecnologia do Ambiente Construído (ENTAC), São Paulo, 1993. Anais: avanços em tecnologia e gestão da produção de edificações. São Paulo, Escola Politécnica da USP, 1993. v. 2, p. 933-40.

MARCONI, Marina de Andrade; LAKATOS, Eva Maria. Metodologia do Trabalho Científico. 7ạ edição, 4a reimpressão. São Paulo: Editora Atlas, 2009. 


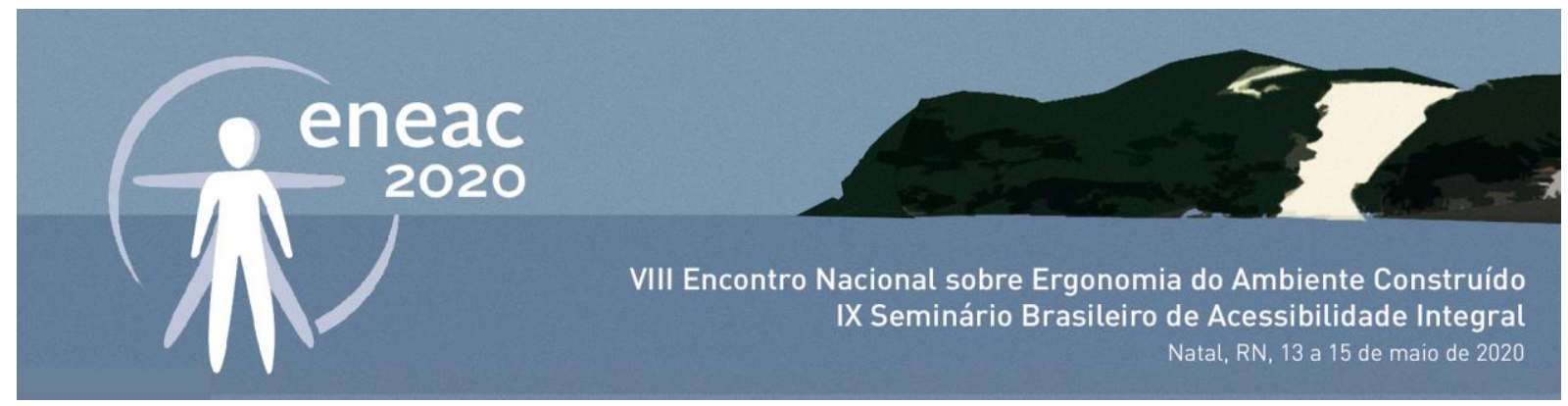

MACIEL, A. M., COSTA FILHO, L. L. and VILLAROUCO, V. A qualidade calmante percebida em cenas de recepções hospitalares. p.798-807. In: VII ENEAC Encontro Nacional de Ergonomia do Ambiente Construído e VIII Seminário Nacional de Acessibilidade Integral, Recife. Anais... Fortaleza, UFC.2018.

RAPOPORT, A. The meaning of the built environment: a nonverbal communication approach. Tucson: University of Arizona, 1990.

RODRIGUEZ-MARÍN, J. R. Psicologia Social de la Salud. Madri: Sínteses, 1995.

ULRICH R. S., Effects of interior design on wellness: theory and recent scientific research, in: "Journal of Health Care Interior Design", v. 3, n. 1, 1991, pp. 97-109.

ULRICH, Roger S. et al. Stress recovery during exposure to natural and urban environments. Journal of environmental psychology, v. 11, n. 3, 1991, pp. 201-230.

ULRICH, Roger. View through a window may influence recovery. Science, v. 224, n. 4647, 1984, pp. 224-225.

VAN DEN BERG, A. E. \& CUSTERS, M. H. G. Gardening promotes neuroendocrine and affective restoration from stress. Journal of Health Psychology, 16(1), 3-11, 2011.

VASCONCELOS, Renata T. B. Humanização de Ambientes Hospitalares: Características Arquitetônicas responsáveis pela integração interior-exterior (Mestrado em Arquitetura), Universidade Federal de Santa Catarina, 2004.

VELARDE, M.D., FRY, G. and TVEIT, M. Health Effects of Viewing Landscapes: Landscape Types in Environmental Psychology. Urban Forestry and Urban Greening, 6, 199-212, 2007.http://dx.doi.org/10.1016/j.ufug.2007.07.001 